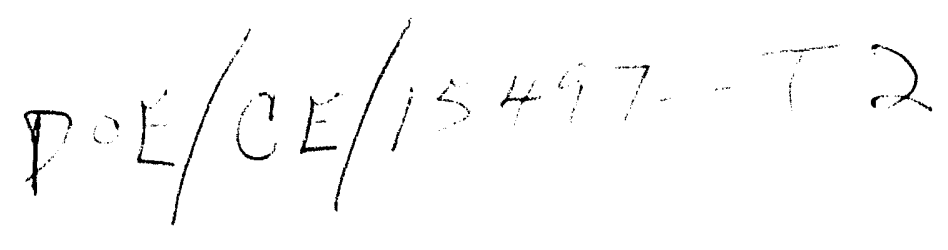

DOE/CE/15497--T2

DE93 000735

Instrument Number DE-FG01-91CE15497

United States Department of Energy

Quarterly Report

Period 6-16-92 through 9-15-92

Submitted by

$\mathrm{Nu}$-Bore Systems

Wichita Falls, Texas

Mr. Charles Koster

\title{
DESIGN, BUILD, DEVELOP AND TEST A FIELDWORTHY SPIRAL TOOL AND PACKER FOR CASING REPAIR
}

\section{DISCLAIMER}

This report was prepared as an account of work sponsored by an agency of the United States Government. Neither the United States Government nor any agency thereof, nor any of their employees, makes any warranty, express or implied, or assumes any legal tiability or responsibility for the accuracy, completeness, or usefulness of any information, apparatus, product, or process disclosed, or represents that its use would not infringe privately owned rights. Reference herein to any specific commercial product, process, or service by trade name, trademark, manufacturer, or otherwise does not necessarily constitute or imply its endorsement, recommendation, or favoring by the United States Government or any agency thereof. The views and opinions of authors expressed herein do not necessarily state or reflect those of the United States Government or any agency thereof.

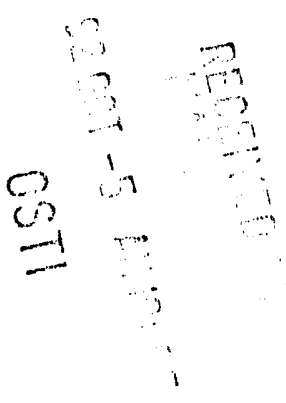




\section{Design, Build, Develop, and Test A Fieldworthy Spiral \\ Tool and Packer for Casing Repair}

\subsection{Introduction}

The oil and gas industry has an opportunity for protecting the environment and conserving resources by sealing wellbore leakage in damaged wells. This leakage has various causes, such as corrosion damage, cracked or otherwise defective casing, and unwanted perforations. The opportunity comes in the form of a newly designed and partially developed method for internally sealing well casing or tubing to prevent leakage. Once this method is fully developed, our country can realize significant financial savings in addition to the environmental protection and resource conservation benefits.

A new method for sealing casing is currently under development by Nu-Bore Systems. The method involves internally lining a section of the wellbore with a multi-layer spiral wrapping of a high strength, corrosion resistant metal interleaved with a high bond strength, resilient epoxy. The high strength metal is preferably a copper based alloy hardened is a very high strength in order to resist the internal and external pressures of downhole environments. The epoxy adhesive formulation is one that forms a bond between the steel inner wall of the casing and copper alloy strip. The copper alloy strip spiral wraps are interleaved with epoxy, and the whole system provides a high level of outward directed spring force and, thus, resists both internal and externally directed forces. This method has been assessed by the Department of Energy, and the magnitude of the oilfield need and the technology are described in a DoE report entitled, "Downhole Casing Repair System" (OERI Number 013152). In this report, the cost savings to the nation's energy program was estimated to be in the range of hundreds of millions of dollars per year, and the method was judged technically feasible once certain well defined engineering obstacles are overcome.

\subsection{Background of the Program}

The spiral lining method reduces cost because of its modular tooling and simple process. It increases reliability by using materials resistant to corrosive conditions, and it makes it much simpler to get equipment to remote wellsite locations. The Nu-Bore method needs further development, however, to take it from its current stage in which it is limited to relatively short lining lengths, to a stage closer to commercial operation in which it will be capable of very long lengths. 
The current program involves development of a segmented connecting joint for an inflatable rubber packer. Packers are tubular components with a relatively thick wall and are made from vulcanized rubber reinforced with cord much like vehicular tires. They are used in several steps of the spiral sealing method, mainly for firmly anchoring the ends of the downhole tools during installation and for applying outward pressure at the lining/casing interface during the cure cycle for the epoxy adhesive.

In theory, the spiral lining process has no length limitation. In practice however, as the length of lining increases, the lenigti of the pressure cure packer must be increased to match the finished length of the lining itself. The packer currently used in the Nu-Bore method is approximately 40 feet long. This becomes the limiting length of the spiral wrapped lining.

For a lining that is several hundred feet long, a long coiled rubber packer would be required. This would be somewhat difficult to transport and deploy, and extremely difficult to manufacture. If long packers could be built up from smaller segments, manufacture would be simpler and less expensive, and packers would be far easier to transport and to work with in the field. Another consideration is the fact that if a long packer is damaged, begins to leak, or becomes distorted, the entire unit is probably unusable. With a segmented packer, only those lengths affected would need replacement.

The objective of this program, therefore, is to develop a joint between packer segments that is easily assembled before lowering downhole and easily disassembled after the sealing job is done. In addition, this tool joint must expand uniformly as though it were a part of the rubber and must not fail under the relatively high pressure of the epoxy cure cycle.

The overall goal of the work is to design, build, develop, and test a spiral tool and packer into a single universal tool that can repair casings with diameters varying from 4.5 to 7 inches.

Task 1. Define, analyze, and complete the engineering requirements for the subject tool system.

Task 2. Perform the engineering design. 
Task 3. Complete the engineering drawings for the tool system, including both the overall layout and the individual components.

Task 4: Complete a materials list, and purchase the materials.

Task 5. Establish test parameters for the tool system.

Task 6. Build a prototype.

Task 7. Perform tests to validate performance of the individual components and the overall assembly.

Task 8. Prepare final report for DOE.

\subsection{Engineering Program Plan}

The action plan of this program is divided into the following areas:

- Define and analyze engineering requirements for the system.

- Produce layout drawings of the tooling design.

- Select special manufacturing treatments for key components.

- Establish test parameters.

- Build engineering model of the segmented packer joint.

- Perform testing to validate performance of components and overall assembly. 
These tasks can be further broken down as follows:

\section{A. Engineering:}

Establish design parameters

Detail joint test model

Redesign and Test as required

Design and Detail Full Size Unit

Design Required Tooling (vulcanizing molds, etc.)

Test, redesign, and retest as required .

Document for ultimate production

\section{B. Manufacturing}

Fabricate Test Models (metal components)

Fabricate mold model

Lay up molded test model

Fabricate prototype mold

Lay up molded prototype

Fabricate test equipment as required

C. Test

Test models

Test prototype

\subsection{Program Status}

\subsection{Engineering}

- A specification for the prototype segmented packer joint was developed. The specification is general, and it is expected to undergo some modification as the test program progresses. The format has been established though, and this will help communication between the design, manufacturing, and test tasks of the project, and will assist in the ultimate transfer of the projects end results into practice. 
- Equipment and material were purchased, and the basic test system was fabricated at the site at which testing will take place. The system consists of a horizontal cylindrical steel container with built-in test stations from which measurements of the outer diameter of the joint can be measured, as water pressure is ramped up to the ultimate pressure capability of the joint or until it reaches the program target maximum pressure. All other hardware for day-to-day testing, including pressure pumping and measurement systems, are installed and debugged, and the initial tests have been initiated.

- An engineering layout of the initial prototype was completed, and all part drawings of the components were made.

\subsection{Manufacturing}

- All parts of the initial prototype joint were submitted to outside vendors. Two firm price bids were received. The bids were reviewed and a purchase

order given to the lowest bidder. The work was completed, and the parts were received. They were inspected and accepted.

- Mechanical parts of the initial prototype joint were assembled and delivered to the rubber manufacturing and vulcanizing source. The first complete jacker was received in May, and pressure testing began soon after that.

\subsection{Testing}

- In the first program quarter, pressure testing of the initial expansion segment prototype resulted i/ 1 an end fitting failure at close to $400 \mathrm{psi}$. The joint itself performed mechanically as desired with essentially a full packer diameter achiever at the joint. The failure at the packer end was analyzed thoroughly and the rubber emoved from the metallic components and prepared for a second rubber sppiication.

- Prototype evaluation is currently proceeding at an accelerated pace in the second and third program quarters. Test Set Number 10 is currently undergoing pressure testing. 
- A test set consists of from one to four segmented packers. The first nine test sets consisted of a segmented packer connection with two end ittings. Pressure testing to failure yielded an increasing pressure capability starting at Test Set Number 1 failing at 400 psi up to Test Set Number Nine failing at 1200 psi. Throughout this test sequence, failure always occurred at an end fitting. The segmented connection always performed as desired with inflation occurring uniformly across the joint. Considering these results it was decided to construct four new prototype test units, eliminating the somewhat complicated and expensive expansion segment connection, and focusing for the moment on improving and testing the end connection only. Test Set Number 10 is comprised of this set of four new-test units. They have been processed through the rubber layup and vulcanization process and are now beginning the pressure test phase.

- Since every failure thus far in the program has occurred at an end fitting, design has now been concentrated on this problem. A new and innovative end fitting design is being incorporated and progress is being made as indicated by continuing success in reaching higher and higher pressure capability.

- The spiral winding apparatus has been performing satisfactorily in repeated testing.

\subsection{Future Work}

In the next (third) quarter on this program we expect that testing will be completed on approximately three more Test Sets. We intend to demonstrate conclusively that we can meet or exceed the program goal of 1000 psi internal expansion pressure with uniform outward contact with the inner casing wall. The new end joint concept will be proven. It is expected that a final design will follow during the fourth quarter. 

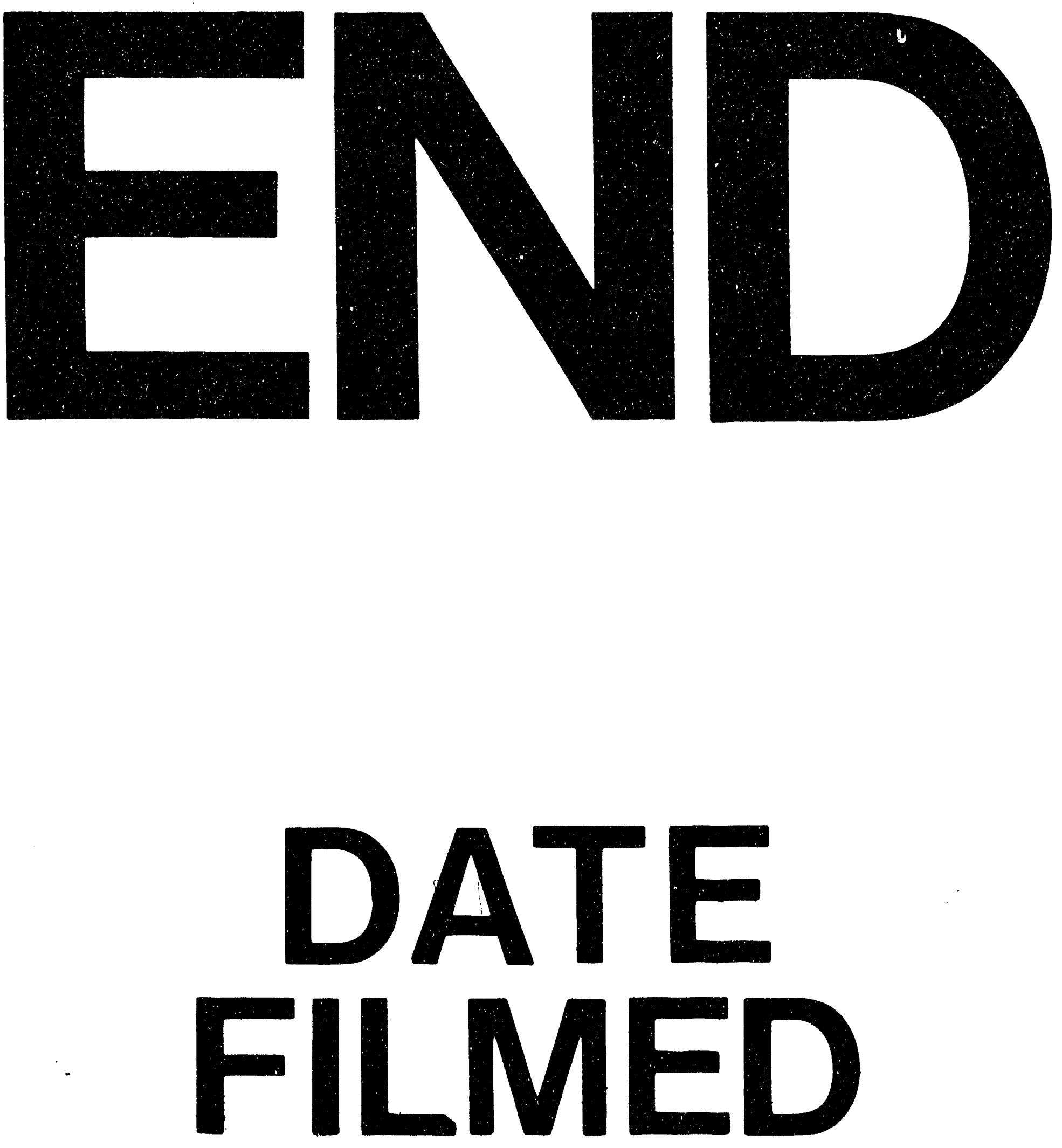

1

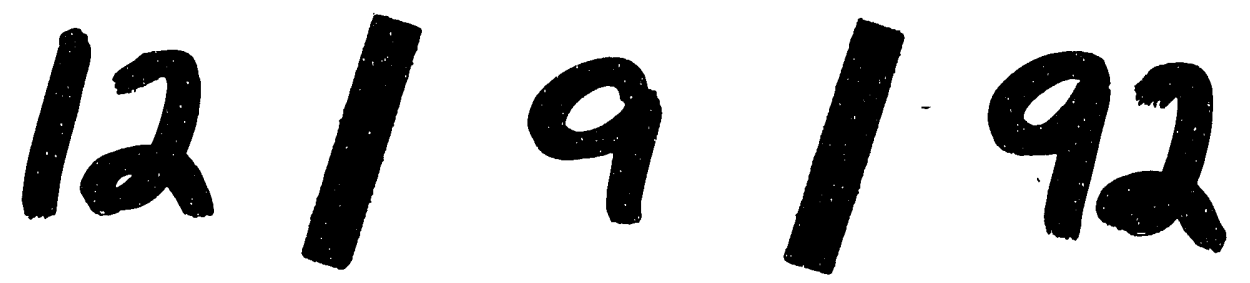


